\title{
Comparison of Pine Needles and Mosses as Bio-Indicators for Polycyclic Aromatic Hydrocarbons
}

\section{Yoshitaka Oishi}

Department of Forest Science, Faculty of Agriculture, Shinshu University, Matsumoto, Japan.

Email: oishiy@shinshu-u.ac.jp

Received May 19 ${ }^{\text {th }}, 2013$; revised June $20^{\text {th }}, 2013$; accepted July $25^{\text {th }}, 2013$

Copyright (C) 2013 Yoshitaka Oishi. This is an open access article distributed under the Creative Commons Attribution License, which permits unrestricted use, distribution, and reproduction in any medium, provided the original work is properly cited.

\begin{abstract}
Polycyclic aromatic hydrocarbons (PAHs) are ubiquitous environmental contaminants known to be hazardous to human health. Pine needles and mosses are useful bio-indicators for assessing PAH pollutions; however, the differences in their PAH uptake mechanisms have not been sufficiently discussed. In this study, the properties of pine needles and mosses as bio-indicators of PAHs were investigated on the basis of differences in their PAH profiles. Five sets each of pine needle and moss samples were collected from circular sampling plots and analyzed for 16 PAHs. A comparison of PAH profiles revealed that the proportion of lower molecular weight PAHs (2 - 3 aromatic rings; LMW PAHs) was significantly higher in pine needles $(78.5 \% \pm 4.8 \%)$ than in mosses $(35.4 \% \pm 6.8 \%)$. In contrast, the proportion of higher molecular weight PAHs (5 - 6 aromatic rings; HMW PAHs) was lower in pine needles $(4.3 \% \pm 2.9 \%)$ than in mosses $(25.1 \% \pm 3.3 \%)$. Further, the combination of PAH isomer ratios showed that PAH sources between pine needles and mosses were not the same. These differences were explained by their uptake mechanisms and partly by the absorption of PAHs from soil particles by mosses. These findings indicate that pine needles are useful for assessing airborne LMW PAH pollution, whereas mosses can be integrated indicators for assessing complex HMW PAH pollution of the atmospheric and soil environments. On the basis of these properties, the usefulness of these bio-indicators should also be evaluated according to the objective of the assessment and the areas where they are applied.
\end{abstract}

Keywords: Air Pollution; Cuticle Layer; Environmental Monitoring; Indicator Species; Uptake Mechanism

\section{Introduction}

Polycyclic aromatic hydrocarbons (PAHs) are a group of ubiquitous environmental contaminants that consist of more than 100 organic compounds with two or more fused aromatic rings. PAHs are emitted into the atmosphere through incomplete combustion due to both anthropogenic and natural sources [1]. Anthropogenic sources of PAH are generally human activities that produce energy, such as vehicular movement, domestic heating, industrial processes, and electric power generation [2]. In urban areas, motor vehicle exhaust is one of the dominant sources of these persistent organic pollutants [3]. Several PAHs are known to be hazardous to human health due to their mutagenic and carcinogenic properties $[1,4]$, and concerns regarding the monitoring and regulation of the quantity of PAHs in ambient air have been increasing.

Aerosolized PAHs can be present in either a gaseous or particle-bound phase. These phases are determined by air temperature, the physicochemical characteristics of the compound, and the characteristics of the absorbing surface [5]. In general, 2 - 3-ring PAHs, which have relatively low molecular weight (LMW PAHs), exist primarily in the gas phase of the atmosphere. PAHs with $5-6$ rings, which have relatively high molecular weight (HMW PAHs), are more likely to be present in the particle-bound phase $[1,6]$. Furthermore, in 4-ring PAHs at intermediate vapor pressures, a temperature-dependent gas/particle phase partitioning occurs. These phases are closely related to the uptake or absorption of PAHs into plants and soils [7-9].

Vegetation has been used as a bio-indicator to identify point sources of pollutants and to determine regional and global contamination patterns [10]. This approach is based on the concept that the amounts and composition of contaminants in plants provide accumulative and timeintegral estimates of the concentrations of airborne contaminants [10]. In particular, pine needles [3,8,11-15], lichens [16-19], and mosses [7,20-26] are good bio-in- 
dicators of airborne contaminants.

It is essential to understand the properties of bio-indicators in order to conduct effective bio-monitoring. The mechanisms of PAH uptake have been compared between pine needles and lichens [17], pine needles and mosses [22,26], and mosses and lichens [26]. In one of these comparisons, Augusto et al. [26] showed that the PAH profile of pine needles (Pinus pinea) and lichen (Parmotrema hypoleucinum) was substantially different from that of the soil, but similar to that of the air. These researchers also reported that the relatively large surface area of lichens made them more efficient at absorbing PAHs than pine needles.

In a case study comparison between pine needles and mosses, previous studies [22,42] reported differences in the composition of accumulated PAHs in these two types of vegetation. Further, Migaszewski et al. [26] reported that the PAH concentration and profile of mosses (Hylocomium splendens) were different from those of pine needles (Pinus sylvestris), as were the PAH concentrations and profiles of mosses and lichens (Hypogymnia physodes). These results indicate that mosses tend to preferentially accumulate HMW PAHs to a greater degree than pine needles and lichens. However, this trend requires careful consideration because the plant samples used in these studies were collected from locations that were an unknown distance apart. Therefore, local PAH sources (e.g., vehicle exhaust from nearby paved roads) may have affected the PAH accumulation in these plant types.

The mechanisms of PAH uptake that might affect observed differences in PAH accumulation in mosses and other plant groups have not been examined or discussed. However, understanding PAH uptake is important if mosses are to be used as bio-indicators for PAH assessment. Comparison of the mechanisms of PAH uptake by mosses with those of pine needles can be particularly useful, as pine needles are the most commonly used bio-indicators for PAHs. In the present study, differences in the composition of the PAHs accumulated in pine needles and mosses are discussed. Determination of the differences in PAH uptake by pine needles and mosses can provide fundamental understanding that contributes to further extension of bio-monitoring for PAH assessment.

\section{Materials and Methods}

\subsection{Sampling Area}

Pine needle and moss samples were collected from an area at the center of Kyoto City $\left(34^{\circ} 59^{\prime} \mathrm{N}, 135^{\circ} 44^{\prime} \mathrm{E}\right)$, capital of Kyoto Prefecture, Japan. Kyoto is an inland city that covers part of the northern half of the Kyoto (Yamashiro) Basin. The mean monthly temperatures range from $8.9^{\circ} \mathrm{C}$ in January to $23.9^{\circ} \mathrm{C}$ in August and the average annual precipitation is $1545 \mathrm{~mm}$. Five circular sampling plots (diameter: $2 \mathrm{~m}$ ) were selected in a green space in Kyoto City, where sufficient plant samples were available (Figure 1). These plots were located $300-350$ $\mathrm{m}$ from any main road.

\subsection{Plant Sampling and Pre-Treatment}

Pinus thunbergii Parl. and Hypnum plumaeforme Wilson were selected as the species of pine needle and mosses to sample, respectively. These species are distributed widely throughout urban areas and have previously been used as bio-indicators of airborne trace elements $[7,8]$.

Plant samples were collected from each plot in February 2010. Two-year-old pine needles on trees that were not growing within the crown projection of any other trees were collected from a point $50-100 \mathrm{~cm}$ above the ground.

Moss samples that were outside of the crown projection of any trees were collected from the ground. In order to obtain homogeneous samples, samples were collected from several points within each 2-m plot and the samples from each plot were grouped together for analysis. Residual soil and other litter were carefully removed from the collected pine needle and moss samples. Only the green and brown-green tips of moss samples were collected for subsequent analysis. The brown (dead) lower

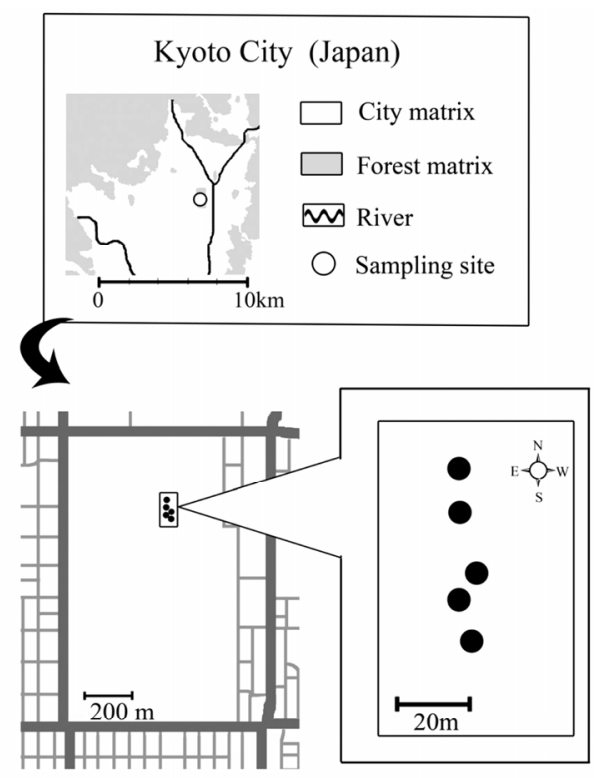

Sampling site (enlarged view)

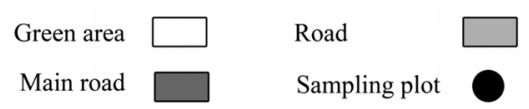

Figure 1. Location of sampling site and sampling plots. The upper figure indicates the location of the sampling site in Kyoto City and the lower figure contains a magnified view of the site. 
parts of mosses were not analyzed. The average length of sampled moss tips was $2.67 \pm 0.47 \mathrm{~cm}$ (mean $\pm \mathrm{SD}$ ), as determined by measurement of 100 samples selected randomly from among all samples. Plant samples were wrapped in aluminum foil, air-dried at ambient temperature, and stored in paper and sealed polyethylene bags in the dark at room temperature until PAH analysis.

\subsection{Sample Analysis}

Homogenized samples $[26.9 \pm 5.9 \mathrm{~g}$ for pine needles and $14.5 \pm 3.1 \mathrm{~g}$ for moss samples (mean $\pm \mathrm{SD}$ )] were dried and Soxhlet-extracted in toluene overnight followed by cleaning with alkaline silica gel. Samples were then analyzed using gas chromatography with high-resolution mass spectrometric detection (GC/HRMS). GC/HRMS analyses were performed using a Micromass AutoSpec Ultima HRMS equipped with an Agilent 6890N GC. The GC was fitted with a HP-5 capillary column (i.d.: $30 \mathrm{~m} \times$ $0.25 \mathrm{~mm}$; film thickness: $0.25 \mu \mathrm{m}$ ). The temperature of the capillary column was $50^{\circ} \mathrm{C}$ for 1 min after injection, increased at a rate of $14^{\circ} \mathrm{C} / \mathrm{min}$ to $220^{\circ} \mathrm{C}$, increased at a rate of $7^{\circ} \mathrm{C} / \mathrm{min}$ to $300^{\circ} \mathrm{C}$, and held at $300^{\circ} \mathrm{C}$ for $40 \mathrm{~min}$. Splitless injection was used to inject $1.0 \mu \mathrm{l}$ of the final extract into the GC column at an injection temperature of $300^{\circ} \mathrm{C}$. The MS was operated under positive EI conditions (70 eV electron energy), and data were obtained in selected ion monitoring (SIM) mode. The following 16 PAHs were analyzed: naphthalene (NAP), acenaphthene (ACE), acenaphthylene (ACL), anthracene (ANT), fluorene (FLU), phenenthrene (PHE), benz [a] anthracene (BaA), chrysene (CHR), fluoranthene (FLR), pyrene (PYR), benzo [a] pyrene $(\mathrm{BaP})$, benzo [b] fluoranthene $(\mathrm{BbF})$, benzo $[\mathrm{k}]$ fluoranthene $(\mathrm{BkF})$, dibenz $[\mathrm{a}, \mathrm{h}]$ anthracene (DBA), benzo [g, h, i] perylene (BPE), and indeno [1,2,3-cd] pyrene (INP). Deuterated surrogate standards (naphthalene-d8, acenaphthylene-d8, phenanthrene$\mathrm{d} 10$, benz [a] anthracene-d12, chrysene-d12, fluoranthene-d10, benzo [a] pyrene-d12, benzo [b] fluoranthene$\mathrm{d} 12$, benzo $[\mathrm{g}, \mathrm{h}, \mathrm{i}]$ perylene-d12, benzo [k] pyrene-d12, indeno [1,2,3-cd] pyrene-d12, and dibenzo [a, h] anthraxcene-d14) were injected prior to each sample extraction for quantification.

\subsection{Quality Assurance and Quality Control}

Quality assurance and quality control were maintained by monitoring on a batch-by-batch basis. A method blank, spiked blank, and surrogates were analyzed between each batch of five samples. The surrogates were pure isotopically-labeled compounds with behaviors that mirror those of the analytes of interest. The average recovery of surrogates was $93 \%$ for pine needle samples and $86 \%$ for moss samples. The overall quality control for this analysis met the acceptability criteria. All PAH analysis was performed by ERI (Tokyo, Japan) and Maxxam Analytics Inc. (Mississauga, Ontario, Canada).

\subsection{Comparison of PAHs between Pine Needles and Mosses}

To investigate the differences in the uptake of various PAHs by pine needles and mosses, the 16 analyzed PAHs were classified into three PAH groups based on the number of aromatic rings each contained ( 2 - 3 rings, 4 rings, and 5 - 6 rings). The proportion of the total $\mathrm{PAH}$ for pine needles that was in each of these PAH groups was compared to that for mosses using Student's t-tests. Total PAH in pine needles and mosses was also compared using Student's t-tests. R software [27] was used for all statistical tests.

\subsection{PAH Sources}

Previous studies have shown that PAH sources may be assessed based on the PAH isomer ratios, under the assumption that isomeric PAHs behave similarly and/or undergo similar environmental transformations during transportation from the emitting sources to the final contaminated location [28,29]. However, other studies have suggested that this apportionment is not always valid because isomer ratios change, particularly during atmospheric transport [30,31]. Therefore, in the present study, $\mathrm{PAH}$ isomer ratios were used to determine whether the PAHs that accumulated in pine needles and mosses were of the same origin. One of the most frequently used isomer ratios for evaluation of PAH sources is the combination of ANT/(ANT + PHE) and FLU/(FLU + PYR) [29, 32]. Therefore, these isomer ratios were used in the present study.

\section{Results}

\subsection{PAH Concentration}

Table 1 shows the total concentration of the 16 PAHs in pine needle and moss samples. In pine needle samples, the total PAH content was $122.6 \pm 50.5 \mathrm{ng} \cdot \mathrm{g}^{-1}$ dry weight and in moss samples, total PAH content was 44.5 $\pm 10.7 \mathrm{ng} \cdot \mathrm{g}^{-1}$ dry weigh (mean $\pm \mathrm{SD}$ ). The percentage contribution to the total PAH content by each individual compound is shown in Figure 2. NAP was the predominant PAH in the pine needle samples $(29.5 \%)$, followed by PHE (26.8\%), FLU (16.3\%), and FLR (10.7\%). In moss samples, PYR, PHE, FLR, and NAP concentrations were substantial $(18.4 \%, 15.7 \%, 13.0 \%$, and $12.6 \%$, respectively). NAP, ACL, ACE, FLU, and PHE were primarily detected in the pine needle samples, while other compounds such as $\mathrm{BaA}, \mathrm{PYR}, \mathrm{BaP}, \mathrm{BbF}, \mathrm{BkF}, \mathrm{BPE}$, and INP were largely found in moss samples. The total $\mathrm{PAH}$ content of pine needles was significantly higher 


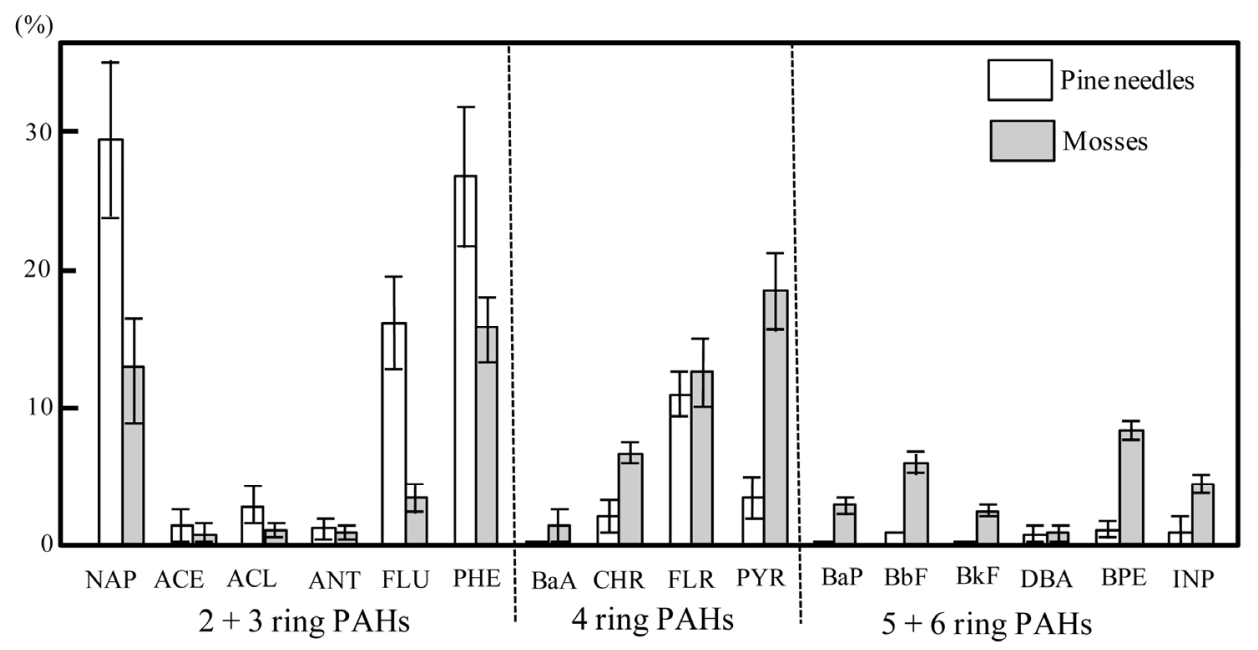

Figure 2. Percentage contribution to total polycyclic aromatic hydrocarbons (PAHs) in pine needles (Pinus thunbergii) and mosses (Hypnum plumaeforme) by individual compounds (Mean \pm SD). Bars represent standard deviations.

Table 1. PAH concentrations in pine needles (Pinus thunbergii Parl.) and mosses (Hypnum plumaeforme Wilson) (dry weight: $n g \cdot g^{-1}$; Mean \pm SD).

\begin{tabular}{ccc}
\hline PAHs & Pine Needle $(\mathrm{n}=5)$ & Moss $(\mathrm{n}=5)$ \\
\hline NAP & $37.20 \pm 20.03$ & $5.62 \pm 1.58$ \\
ACE & $1.30 \pm 0.78$ & $0.21 \pm 0.3$ \\
ACL & $3.34 \pm 0.99$ & $0.55 \pm 0.33$ \\
ANT & $1.49 \pm 1.45$ & $0.57 \pm 0.27$ \\
FLU & $21.44 \pm 11.23$ & $1.58 \pm 0.72$ \\
PHE & $33.60 \pm 15.49$ & $6.92 \pm 1.76$ \\
BaA & $0.22 \pm 0.44$ & $0.78 \pm 0.48$ \\
CHR & $2.92 \pm 1.44$ & $3.00 \pm 0.83$ \\
FLR & $12.52 \pm 4.45$ & $5.72 \pm 1.79$ \\
PYR & $4.70 \pm 3.04$ & $8.24 \pm 2.23$ \\
BaP & $0.06 \pm 0.12$ & $1.43 \pm 0.49$ \\
BbF & $0.86 \pm 0.28$ & $2.82 \pm 1.06$ \\
BkF & $0.44 \pm 0.33$ & $1.12 \pm 0.32$ \\
DBA & $0.58 \pm 0.73$ & $0.12 \pm 0.24$ \\
BPE & $1.04 \pm 0.59$ & $3.76 \pm 0.93$ \\
INP & $0.94 \pm 0.79$ & $2.06 \pm 0.57$ \\
\hline
\end{tabular}

Abbreviations of 16 PAHs: NAP, naphthalene; ACE, acenaphthene; ACL, acenaphthylene; ANT, anthracene; FLU, fluorine; PHE, phenenthrene; BaA, benz [a] anthracene; CHR, chrysene; FLR, fluoranthene; PYR, pyrene; BaP, benzo [a] pyrene; $\mathrm{BbF}$, benzo [b] fluoranthene; $\mathrm{BkF}$, benzo [k] fluoranthene; DBA, dibenz $[\mathrm{a}, \mathrm{h}]$ anthracene; BPE, benzo $[\mathrm{g}, \mathrm{h}, \mathrm{i}]$ perylene; INP, indeno $[1,2,3-c d]$ pyrene.

than that in mosses (d.f. $=8$, t-value $=3.0$ d.f. $=8, \mathrm{p}=$ $0.016)$.

\subsection{Proportion of PAH Groups}

A comparison of the proportion of each $\mathrm{PAH}$ group to the total PAH is shown in Figure 3. The proportions of 2 +3 rings, 4 rings, and $5+6$ rings were $78.5 \% \pm 4.8 \%$, $17.2 \% \pm 2.6 \%$, and $4.3 \% \pm 2.9 \%$ for pine needles and $35.4 \% \pm 6.8 \%, 39.5 \% \pm 4.5 \%$, and $25.1 \% \pm 3.3 \%$ (Mean \pm SD) for mosses, respectively. The proportions of $2+3$ rings were significantly higher in pine needle samples (d.f. $=8$, t-value $=10.4, p<0.01$ ), whereas those of 4 rings and $5+6$ rings were significant higher in moss samples (d.f. $=8, \mathrm{t}$-value $=-8.6, \mathrm{p}<0.01$; d.f. $=8$, $\mathrm{t}$-value $=-9.5, \mathrm{p}<0.01)$. These results also indicate that the proportion of each PAH group to the total decreased rapidly as the number of aromatic rings in the pine needles increased. In contrast, mosses exhibited a slightly less clear decreasing trend.

\subsection{PAH Isomer Ratios}

Plots of the ANT/(ANT + PHE) versus the FLU/(FLU + PYR) ratios for pine needle and moss samples are shown in Figure 4. The ANT/(ANT + PHE) ratio for all samples except one were $<0.1$ (mean $\pm \mathrm{SD}=0.05 \pm 0.02$ for pine needles, $0.07 \pm 0.02$ for mosses). The FLU/(FLU + PYR) ratio for pine needles was around 0.7 (mean \pm SD $=0.74 \pm 0.06$ ) while it was around 0.40 (mean $\pm \mathrm{SD}=$ $0.40 \pm 0.07)$ in moss samples. A cross-plot of these isomer ratios clearly distinguished pine needle samples from moss samples.

\section{Discussion}

The results indicated that LMW PAHs tended to accumulate more readily in pine needles, whereas HMW PAHs were preferably absorbed in moss samples. Additionally, the PAH isomer ratios showed clear differences 


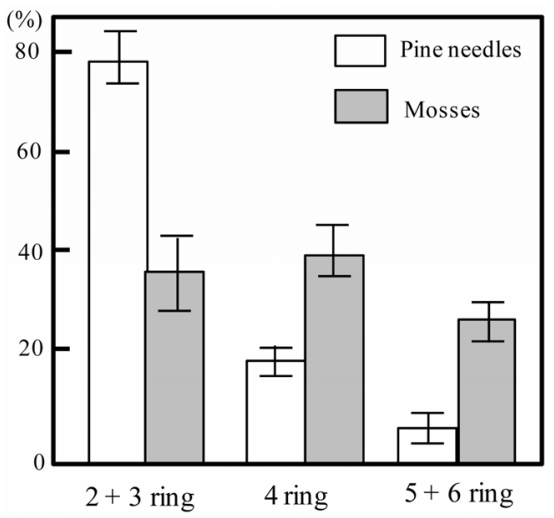

Figure 3. Proportion of total PAH concentration attributable to each of three PAH groups ( 2 - 3 rings, 4 rings, and 5 - 6 rings) in pine needles (Pinus thunbergii) and mosses (Hypnum plumaeforme) (Mean $\pm \mathrm{SD}$ ). Bars represent standard deviations.

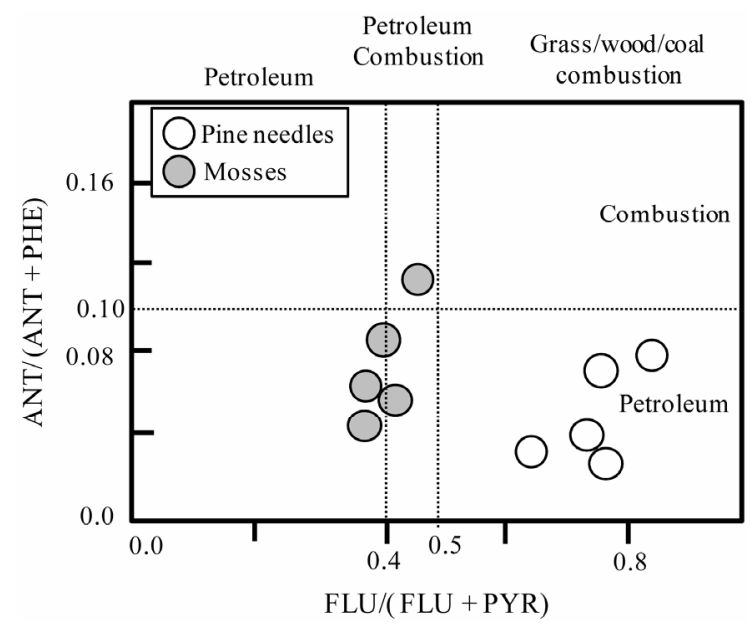

Figure 4. Cross-plot for ANT/(ANT + PHE) and FLU/(FLU + PYR) ratios for pine needle and moss samples. Abbreviations: ANT, anthracene; FLU, fluorine; PHE; phenenthrene; PYR, pyrene.

in the sources of the PAHs in pine needle and moss samples.

\subsection{Uptake Mechanism of PAHs}

The results in this study are in agreement with results of previous studies that reported high concentrations of LMW PAHs in pine needles $[9,10]$ and high concentrations of HMW PAHs in mosses $[7,22,26]$ across different locations. The relatively high concentration of HMW PAHs in mosses can be explained by differences in the leaf structure and PAH uptake mechanism of pine needles and mosses [42]. The leaf properties of bio-indicators (e.g., leaf size, surface morphology, waxy cuticle, and lipid compounds) are important for understanding their PAH profiles [3,33-36]. Piccardo et al. [3] showed that LMW PAHs diffuse and accumulate more readily than
HMW PAHs in pine needle tissues either via the stomata or by diffusion through the cuticle, while HMW PAHs remain in the waxy cuticle layer owing to their strong interactions with the constituent of the cuticle layer. Consequently, the HMW PAHs in the cuticle layer of pine needles are affected more easily by external environmental factors (e.g., rain, temperature, ozone, and solar radiation) that may cause them to be lost from the leaves [3,34]. In contrast, HMW PAHs can be absorbed easily by moss tissues because of they interact weakly with the leaf surface of mosses, which lack a waxy cuticle layer.

These differences in uptake mechanisms can also result in different patterns of PAH absorption from dry/wet deposition in pine needles and mosses.

Mosses effectively absorb dissolved pollutants from precipitation [37], while pine needles mainly take up gaseous PAHs via their stomata or by diffusion [38]. Therefore, the PAHs that accumulate in mosses can be more strongly affected by PAHs dissolved in precipitation than those in pine needles.

The pine needles examined in this study contained a significantly greater total PAH concentration than was contained in mosses. This high PAH content can be explained by the high content of LMW PAHs that were preferentially absorbed in their leaves.

As discussed above, the cuticle layers of pine needles prevent particle-bound PAHs from penetrating into leaf cells; while they effectively accumulate LMW PAHs from the air [3]. Considering the contribution of LMW PAHs to the high amount of PAHs in pine needles (Figure 2), they can be more useful bio-indicators for assessing LMW PAHs than mosses.

\subsection{Other Environmental Factors Affecting the Absorption of PAHs}

In addition to the differences in the leaf uptake mechanisms, the relatively high concentration of HMW PAHs in mosses can also be partly explained by their uptake of PAHs through soil particles [39].

While this absorption route has not been proven experimentally, Kłos et al. [40] used radioactive markers to show that mosses take up heavy metals from soil particles adhering to them. HMW PAHs exist mainly as particles and can, therefore, be easily absorbed into soil [8, 41]. Mosses are likely to absorb HMW PAHs through soil particles in the same manner as they absorb heavy metals.

\subsection{PAH Sources}

The ANT/(ANT + PHE) ratios of most samples in the present study fell predominantly in the petrogenic area $(<0.1)$; though the ratio for mosses tended to be higher 
than that for pine needles. The high FLU/(FLU + PYR) ratios in pine needles $(>0.5)$ indicated that the PAHs in pine needles were released by combustion of coal and biomass. The FLU/(FLU + PYR) ratios in mosses indicated that they were released by petroleum or petroleum combustion. The cross-plots of these PAH ratios indicate that there was a clear separation of the sources of in pine needles and mosses. This difference can reflect the strong influence of wet deposition and soil particles on PAH uptake by mosses.

\section{Conclusions}

This study shows that mosses preferentially accumulate HMW PAHs, while pine needles effectively take up LMW PAHs. This difference in preferential accumulation can be explained by differences in the mechanisms of PAH uptake and the influence of soil particles. These findings indicate that we can assess PAH pollution from diverse perspectives by using a combination of pine needles and mosses as bio-indicators; pine needles are useful for assessing airborne LMW PAH pollution, whereas mosses can be used to asses complex HMW PAH pollution in atmospheric and soil environments.

Previous studies have examined the usefulness of other bio-indicators for PAH assessment. Pine needles are suitable for the evaluation of long-term trends in atmospheric PAHs [11], while it has been proposed that lichens may be useful for the fingerprinting of multisource atmospheric PAH pollution [16] and for the assessment of air quality in natural ecosystems [19]. However, the abilities and usefulness of bio-indicators differ on a caseby-case basis. For example, mosses are not suitable for the assessment of LMW PAH pollution or for assessment of PAHs in areas where mosses are scarce. Therefore, in order to propose effective bio-monitoring for PAHs, the usefulness of bio-indicators should be evaluated according to the objectives of PAH assessment and the areas where they are applied on the basis of their ecology.

\section{Acknowledgements}

The author thanks Professor Kumiko Okubo for critical comments and suggestions for improving this paper. This research was supported by the Global COE Program, "Global Center for Education and Research on Human Security Engineering for Asian Megacities", MEXT, Japan. The study design was approved by the appropriate ethics review board.

\section{REFERENCES}

[1] B. Maliszewska-Kordybach, "Sources, Concentrations, Fate and Effects of Polycyclic Aromatic Hydrocarbons (PAHs) in the Environment. Part A: PAHs in Air," Polish
Journal of Environmental Studies, Vol. 8, No. 3, 1999, pp. 131-136.

[2] A. M. Mastral and M. S. Callén, "A Review on Polycyclic Aromatic Hydrocarbon (PAH) Emission from Energy Generation," Environmental Science \& Technology, Vol. 34, No. 15, 2000, pp. 3051-3057. doi:10.1021/es001028d

[3] M. T. Piccardo, M. Pala, B. Bonaccurso, A. Stella, A. Redaelli, G. Paola and F. Valério, "Pinus nigra and Pinus pinaster Needles as Passive Samplers of Polycyclic Aromatic Hydrocarbons," Environmental Pollution, Vol. 133, No. 2, 2005, pp. 293-301. doi:10.1016/j.envpol.2004.05.034

[4] E. Aas, J. Beyer, G. Jonsson, W. L. Reichert and O. K. Andersen, "Evidence of Uptake, Biotransformation and DNA Binding of Polyaromatic Hydrocarbons in Atlantic Cod and Corkwing Wrasse Caught in the Vicinity of an Aluminium Works," Marine Environmental Research, Vol. 52, No. 3, 2001, pp. 213-229. doi:10.1016/S0141-1136(00)00269-5

[5] J. F. Pankow, "Review and Comparative Analysis of the Theories on Partitioning between the Gas and Aerosol Particulate Phases in the Atmosphere," Atmospheric Environment, Vol. 21, No. 11, 1987, pp. 2275-2283. doi:10.1016/0004-6981(87)90363-5

[6] T. F. Bidleman, "Atmospheric Processes. Wet and Dry Deposition of Organic Compounds Are Controlled by Their Vapor-Particle Partitioning," Environmental Science \& Technology, Vol. 22, No. 4, 1988, pp. 361-367. doi: $10.1021 / \mathrm{es} 00169 \mathrm{a} 002$

[7] X. Liu, G. Zhang, K. C. Jones, X. Li, X. Peng and S. Qi, "Compositional Fractionation of Polycyclic Aromatic Hydrocarbons (PAHs) in Mosses (Hypnum plumaeformae WILS.) from the Northern Slope of Nanling Mountains, South China," Atmospheric Environment, Vol. 39, No. 30, 2005, pp. 5490-5499.

doi:10.1016/j.atmosenv.2005.05.048

[8] Z. Wang, J. W. Chen, P. Yang, F. L. Tian, X. L. Qiao, H. T. Bian and L. K. Ge, "Distribution of PAHs in Pine (Pinus thunbergii) Needles and Soils Correlates with Their Gas-Particle Partitioning," Environmental Science \& Technology, Vol. 43, No. 5, 2009, pp. 1336-1341. doi:10.1021/es802067e

[9] Z. Wang, X. Ma, G. Na, Z. Lin, Q. Ding and Z. Yao, "Correlations between Physicochemical Properties of PAHs and Their Distribution in Soil, Moss and Reindeer Dung at Ny-Ålesund of the Arctic," Environmental Pollution, Vol. 157, No. 11, 2009, pp. 3132-3136. doi:10.1016/i.envpol.2009.05.014

[10] S. L. Simonich and R. A. Hites, "Organic Pollutant Accumulation in Vegetation," Environmental Science \& Technology, Vol. 29, No. 12, 1995, pp. 2905-2914. doi:10.1021/es00012a004

[11] J. Klánová, P. Čupr, D. Baráková, Z. Šeda, P. Anděl and I. Holoubek, "Can Pine Needles Indicate Trends in the Air Pollution Levels at Remote Sites?" Environmental Pollution, Vol. 157, No. 12, 2009, pp. 3248-3254. doi:10.1016/j.envpol.2009.05.030

[12] E. Lehndorff and L. Schwark, "Biomonitoring Airborne 
Parent and Alkylated Three-Ring PAHs in the Greater Cologne Conurbation I: Temporal Accumulation Patterns," Environmental Pollution, Vol. 157, No. 4, 2009, pp. 1323-1331. doi:10.1016/j.envpol.2008.11.037

[13] N. Ratola, J. M. Amigo and A. Alves, "Levels and Sources of PAHs in Selected Sites from Portugal: Biomonitoring with Pinus pinea and Pinus pinaster Needles," Archives of Environmental Contamination and Toxicology, Vol. 58, No. 3, 2010, pp. 631-647. doi:10.1007/s00244-009-9462-0

[14] N. Ratola, A. Alves and E. Psillakis, "Biomonitoring of Polycyclic Aromatic Hydrocarbons Contamination in the Island of Crete Using Pine Needles," Water, Air, \& Soil Pollution, Vol. 215, No. 1-4, 2011, pp. 189-203. doi:10.1007/s11270-010-0469-y

[15] P. Tremolada, V. Burnett, D. Calamari and K. C. Jones, "Spatial Distribution of PAHs in the UK Atmosphere Using Pine Needles," Environmental Science \& Technology, Vol. 30, No. 12, 1996, pp. 3570-3577. doi:10.1021/es960269b

[16] S. Augusto, C. Máguas, J. Matos, M. J. Pereira, A. Soares and C. Branquinho, "Spatial Modeling of PAHs in Lichens for Fingerprinting of Multisource Atmospheric Pollution," Environmental Science \& Technology, Vol. 43, No. 20, 2009, pp. 7762-7769. doi:10.1021/es901024w

[17] S. Augusto, C. Máguas, J. Matos, M. J. Pereira and C. Branquinho, "Lichens as an Integrating Tool for Monitoring PAH Atmospheric Deposition: A Comparison with Soil, Air and Pine Needles," Environmental Pollution, Vol. 158, No. 2, 2010, pp. 483-489. doi:10.1016/j.envpol.2009.08.016

[18] M. Blasco, C. Domeño and C. Nerín, "Use of Lichens as Pollution Biomonitors in Remote Areas: Comparison of PAHs Extracted from Lichens and Atmospheric Particles Sampled in and around the Somport Tunnel (Pyrenees)," Environmental Science \& Technology, Vol. 40, No. 20, 2006, pp. 6384-6391. doi:10.1021/es0601484

[19] M. Blasco, C. Domeño and C. Nerín, "Lichens Biomonitoring as Feasible Methodology to Assess Air Pollution in Natural Ecosystems: Combined Study of Quantitative PAHs Analyses and Lichen Biodiversity in the Pyrenees Mountains," Analytical and Bioanalytical Chemistry, Vol. 391, No. 3, 2008, pp. 759-771. doi:10.1007/s00216-008-1890-6

[20] A. Gałuszka, "Distribution Patterns of PAHs and Trace Elements in Mosses Hylocomium splendens (Hedw.) B.S.G. and Pleurozium schreberi (Brid.) Mitt. from Different Forest Communities: A Case Study, South-Central Poland," Chemosphere, Vol. 67, No. 7, 2007, pp. 14151422. doi:10.1016/j.chemosphere.2006.10.010

[21] R. Gerdol, L. Bragazza, R. Marchesini, A. Medici, P. Pedrini, S. Benedetti, A. Bovolenta and S. Coppi, "Use of Moss (Tortula muralis Hedw.) for Monitoring Organic and Inorganic Pollution in Urban and Rural Sites in Northern Italy," Atmospheric Environment, Vol. 36, No. 25, 2002, pp. 4069-4075. doi:10.1016/S1352-2310(02)00298-4

[22] I. Holoubek, P. Korínek, Z. Seda, E. Schneiderová, I. Holoubková, A. Pacl, J. Tríska, P. Cudlín and J. Cásl- avský, "The Use of Mosses and Pine Needles to Detect Persistent Organic Pollutants at Local and Regional Scales," Environmental Pollution, Vol. 109, No. 2, 2000, pp. 283-292. doi:10.1016/S0269-7491(99)00260-2

[23] V. Krommer, H. G. Zechmeister, I. Roder, S. Scharf and A. Hanus-Illnar, "Monitoring Atmospheric Pollutants in the Biosphere Wienerwald by a Combined Approach of Biomonitoring Methods and Technical Measurements," Chemosphere, Vol. 67, No. 10, 2007, pp. 1956-1966. doi:10.1016/j.chemosphere.2006.11.060

[24] E. Ötvös, I. O. Kozák, K. Fekete, V. K. Sharma and Z. Tuba, "Atmospheric Deposition of Polycyclic Aromatic Hydrocarbons (PAHs) in Mosses (Hypnum cupressiforme) in Hungary," Science of the Total Environment, Vol. 330, No. 1-3, 2004, pp. 89-99. doi:10.1016/j.scitotenv.2004.02.019

[25] N. Skert, J. Falomo, L. Giorgini, A. Acquavita, L. Capriglia, R. Grahonja and N. Miani, "Biological and Artificial Matrixes as PAH Accumulators: An Experimental Comparative Study," Water, Air, \& Soil Pollution, Vol. 206, No. 1-4, 2010, pp. 95-103. doi:10.1007/s11270-009-0089-6

[26] Z. M. Migaszewski, A. Gałuszka and P. Pasławski, "Polynuclear Aromatic Hydrocarbons, Phenols, and Trace Metals in Selected Soil Profiles and Plant Bioindicators in the Holy Cross Mountains, South-Central Poland," Environment International, Vol. 28, No. 4, 2002, pp. 303-313. doi:10.1016/S0160-4120(02)00039-9

[27] R Development Core Team, "R: A Language and Environment for Statistical Computing," R Foundation for Statistical Computing, Vienna, 2012.

[28] T. D. Bucheli, F. Blum, A. Desaules and O. Gustafsson, "Polycyclic Aromatic Hydrocarbons, Black Carbon, and Molecular Markers in Soils of Switzerland," Chemosphere, Vol. 56, No. 11, 2004, pp. 1061-1076. doi:10.1016/j.chemosphere.2004.06.002

[29] M. B. Yunker, R. W. Macdonald, R. Vingarzan, R. H. Mitchell, D. Goyette and S. Sylvestre, "PAHs in the Fraser River Basin: A Critical Appraisal of PAH Ratios as Indicators of PAH Source and Composition," Organic Geochemistry, Vol. 33, No. 4, 2002, pp. 489-515. doi:10.1016/S0146-6380(02)00002-5

[30] H.-M. Hwang, T. L. Wade and J. L. Sericano, "Concentrations and Source Characterization of Polycyclic Aromatic Hydrocarbons in Pine Needles from Korea, Mexico and United States," Atmospheric Environments, Vol. 37, No. 16, 2003, pp. 2259-2267. doi:10.1016/S1352-2310(03)00090-6

[31] X. L. Zhang, S. Tao, W. X. Liu, Y. Yang, Q. Zuo and S. Z. Liu, "Source Diagnostics of Polycyclic Aromatic Hydrocarbons Based on Species Ratios: A Multimedia Approach," Environmental Science \& Technology, Vol. 39, No. 23, 2005, pp. 9109-9114. doi:10.1021/es0513741

[32] A. Navarro-Ortega, N. Ratola, A. Hildebrandt, A. Alves, S. Lacorte and D. Barceló, "Environmental Distribution on PAHs in Pine Needles, Soils and Sediments," Environmental Science \& Technology, Vol. 19, No. 3, 2012, pp. 677-688. doi:10.1007/s11356-011-0610-5

[33] M. Howsam, K. C. Jones and P. Ineson, "PAHs Associ- 
ated with the Leaves of Tree Species. I-Concentrations and Profiles," Environmental Pollution, Vol. 108, No. 3, 2000, pp. 413-424. doi:10.1016/S0269-7491(99)00195-5

[34] V. A. Jouraeva, D. L. Johnson, J. P. Hasset and D. J. Nowak, "Differences in Accumulation of PAHs and Metals on the Leaves of Tilia x euchlora and Pyrus calleryana," Environmental Pollution, Vol. 120, No. 2, 2002. pp. 331-338. doi:10.1016/S0269-7491(02)00121-5

[35] J. Niu, J. Chen, D. Martens, X. Quan, F. Yang, A. Kettrup and K. Schramm, "Photolysis of Polycyclic Aromatic Hydrocarbons Adsorbed on Spruce [Picea abies (L.) Karst.] Needles under Sunlight Irradiation," Environmental Pollution, Vol. 123, No. 1, 2003, pp. 39-45. doi:10.1016/S0269-7491(02)00362-7

[36] D. Wang, J. Chen, Z. Xu, X. Qiao and L. Huang, "Disappearance of Polycyclic Aromatic Hydrocarbons Sorbed on Surfaces of Pine [Pinua thunbergii] Needles under Irradiation of Sunlight: Volatilization and Photolysis," Atmospheric Environment, Vol. 39, No. 25, 2005, pp. 45834591. doi:10.1016/j.atmosenv.2005.04.008

[37] W. Thomas, "Representativity of Mosses as Biomonitor Organisms for the Accumulation of Environmental Chemicals in Plants and Soils," Ecotoxicology and Environmental Safety, Vol. 11, No. 3, 1986, pp. 339-346. doi:10.1016/0147-6513(86)90106-5

[38] E. Lehndorff and L. Schwark, "Biomonitoring of Air Quality in the Cologne Conurbation Using Pine Needles as a Passive Sampler-Part II: Polycyclic Aromatic Hydrocarbons (PAH)," Atmospheric Environments, Vol. 38, No. 23, 2004, pp. 3793-3808. doi:10.1016/j.atmosenv.2004.03.065

[39] Z. M. Migaszewski, A. Gałuszka, J. G. Crock, P. J. Lamothe and S. Dołegowska, "Interspecies and Interregional Comparisons of the Chemistry of PAHs and Trace Elements in Mosses Hylocomium splendens (Hedw.) B.S.G. and Pleurozium schreberi (Brid.) Mitt. from Poland and Alaska," Atmospheric Environment, Vol. 43, No. 7, 2009, pp. 1464-1473. doi:10.1016/j.atmosenv.2008.11.035

[40] A. Kłos, M. Czora, M. Rajfur and M. Wacławek, "Mechanisms for Translocation of Heavy Metals from Soil to Epigeal Mosses," Water, Air, \& Soil Pollution, Vol. 223, No. 4, 2012, pp. 1829-1836. doi:10.1007/s11270-011-0987-2

[41] A. Bozlaker, A. Muezzinoglu and M. Odabasi, "Atmospheric Concentrations, Dry Deposition and Air-Soil Exchange of Polycyclic Aromatic Hydrocarbons (PAHs) in an Industrial Region in Turkey," Journal of Hazardous Materials, Vol. 153, No. 3, 2008, pp. 1093-1102. doi:10.1016/j.jhazmat.2007.09.064

[42] Y. Oishi, "Does Uptake of Polycyclic Aromatic Hydrocarbons (PAHs) Differ between Pine Needles and Mosses?" Journal of Environmental Information Science, Vol. 40, No. 5, 2012, pp. 31-36. 